\title{
Sediment and nutrient behaviour on the River Bandon, Ireland
}

\author{
J. R. Harrington ${ }^{1} \&$ S. T. Harrington ${ }^{2}$ \\ ${ }^{1}$ School of Building and Civil Engineering, Cork Institute of Technology, \\ Ireland \\ ${ }^{2}$ Department of Civil, Structural \& Environmental Engineering, \\ Cork Institute of Technology, Ireland
}

\begin{abstract}
This paper presents aspects of sediment and nutrient behaviour on the River Bandon which is located in the South Western River Basin District in Ireland; it is a relatively large sized river catchment in an Irish context with a catchment area of $608 \mathrm{~km}^{2}$. The river catchment is primarily agricultural with some pockets of urban development. The river is prone to flooding on stretches, features a number of special areas of conservation and is distinguished by both suspended and bed load transport.

Continuous monitoring of turbidity commenced in February 2010. Manual sampling and testing for suspended sediment concentration and a range of species of phosphorous was also undertaken. Analysis shows that turbidity is a suitable surrogate for suspended sediment concentration allowing suspended sediment loads to be analysed from the continuous data. Similarly suspended sediment concentration has been found to correlate well with total and particulate phosphorous allowing phosphorous loads to be analysed using the continuous data.

The annual suspended sediment load was 6012 tonnes, with the highest loads experienced during the winter months. The annual total phosphorous load was found to be 42.9 tonnes with particulate phosphorous accounting for approximately $64 \%$ of this total. High flow storm based events contribute disproportionately to suspended sediment and phosphorous transport.

The rating curve approach applied to the sampled data can provide good estimates of the annual load which has particular relevance to Ireland where the current database of suspended sediment information is limited.
\end{abstract}


Keywords: suspended sediment, turbidity, phosphorous, loads, particulate, Strom based events, rating curve.

\section{Introduction}

The River Bandon is located in the South Western River Basin District in Ireland; it is a relatively large sized river catchment in an Irish context with a catchment area of $608 \mathrm{~km}^{2}$. The river catchment is primarily agricultural with some pockets of urban development. The river is distinguished by engineered works on stretches, and particularly in the environs of the town of Bandon, the main urban settlement on the river.

The river is prone to flooding on specific stretches, features a number of special areas of conservation, exhibits a range of levels of water quality and is distinguished by both suspended and bed load transport.

River improvements works have been undertaken in recent years including dredging works on stretches of river in the town of Bandon; further works are planned by the Irish Office of Public Works (OPW) in the town and downstream in the years 2014 and 2015.

Cork Institute of Technology has been undertaking research work on this river in recent years and this paper focuses primarily on some sediment and nutrient behaviour aspects of the river system. The sampling and testing programme is described and analysis, results and a discussion are presented.

\section{Catchment description}

The River Bandon is located as shown in fig. 1 in the South Western River Basin District (SWRBD), one of eight river basin districts on the island of Ireland established under the EU Water Framework Directive (WFD). The SWRBD covers an area of $11,180 \mathrm{~km}^{2}$ and has a temperate maritime climate with an annual average rainfall level of $1219 \mathrm{~mm}$ at the nearby Cork Airport rainfall gauging station. The River Bandon catchment is divided into two water management units; the upland Bandon/Caha Management Unit which is mountainous with significant rock outcrops and poor soil conditions and the lower River Bandon Management Unit which is primarily agricultural in nature with generally good soil conditions.

The $74 \mathrm{~km}$ long River Bandon emerges at an elevation of $210 \mathrm{~m}$ ordnance datum (O.D.), drains an area of $608 \mathrm{~km}^{2}$ and has an average gradient of $2.8 \mathrm{~m}$ $\mathrm{km}^{-1}$. The river discharges to Kinsale Estuary, which has been identified as being seriously euthrophic due to excess nitrogen. The downstream stretch of the river is influenced by tidal action.

Agricultural land, primarily under pasture and tillage, dominates land use comprising approximately $94 \%$ of the total catchment area. Forestry and urban areas account for $5.4 \%$ and $0.6 \%$ respectively of the catchment; the forested areas are mainly located in the upper catchment area.

An upstream section of the River Bandon in the upland Bandon/Caha Management Unit is designated as a Natura 2000 Special Area of Conservation 
(SAC) site and is designated for the Annex 1 priority Habitat Alluvial Forest and also has good examples of another Annex 1 habitat - floating river vegetation. The SAC has also been identified as containing a population of Freshwater Pearl Mussel; this is one of only a limited number of river catchments in Ireland containing the species.

The main pressures to water quality have been identified as being from diffuse agricultural sources and from subservice domestic wastewater treatment plants [1]. Water quality in the Natura $2000 \mathrm{SAC}$ has not always met protected area objectives. The risk to water quality in the sub-catchment around Bandon town is related to the wastewater treatment plant and the licensed discharge facilities in the area [1]. Two nutrient sensitive areas have been designated in the tidally influenced downstream section of the River Bandon under the EU Urban Wastewater Treatment Regulations (2001).

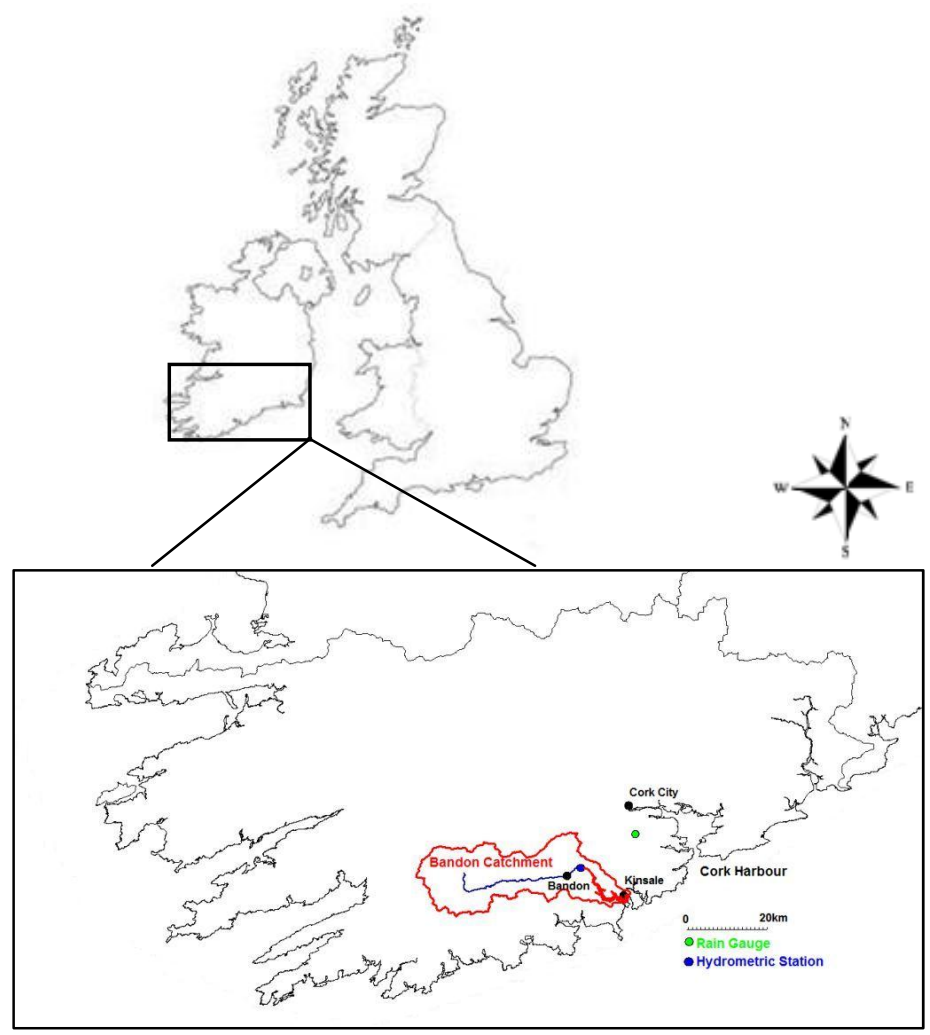

Figure 1: Location of the River Bandon catchment. 


\section{River flows}

River flows on the River Bandon are characterised by frequent flood events in the town of Bandon and downstream. The flooding is fluvial in nature with the town of Bandon originally developed on a flood plain; the extensive development undertaken in the town in recent years has exacerbated the flooding problem with the flood event of November, 2009 considered the worst in living memory. Flood water depths in the town centre during the flood event reached $1.5 \mathrm{~m}$ with an estimated damage cost of $€ 20 \mathrm{~m}$. Records indicate that of the ten highest flood events that have occurred on the river over the past 60 years that four of them have occurred over the past decade indicating the increased potential for damaging floods on the river. An early flood warning system was installed for the town of Bandon in 2009 [2].

Five water level monitoring stations under the control of the OPW are located on the River Bandon, three upstream of the town which were installed in the early 1990s (Longbridge, Ardcahan Bridge and Bealaboy Bridge), one in the town itself installed in 1960 (at Bandon Bridge) and one downstream at the Curranure hydrometric gauging station installed in 1974 which has the only reliable long term data record on the river.

The long average flow rate from the catchment is approximately $15 \mathrm{~m}^{3} / \mathrm{sec}$. Extremal analysis of river flows based on the probability weighted L-moments statistical approach indicates that the GEV Type 2 probability distribution best fit the data; the analysis estimated a 1 in 50 year return period event with a flow rate of $347.5 \mathrm{~m}^{3} / \mathrm{sec}$ with a 1 in 100 year return period flow rate of $437.6 \mathrm{~m}^{3} / \mathrm{sec}$.

\section{Sampling programme and testing}

The main sampling programme has been undertaken at the Curranue hydrometric gauging station located downstream of the town of Bandon. The station has a catchment area of $424 \mathrm{~km}^{2}$ or $70 \%$ of the full river catchment. Digitised 15minute flow date is available at the hydrometric gauging station for the full flow record on the river.

Manual suspended sediment samples were collected using the surface grab technique. One litre sub-samples were collected from the surface grab and subsequently tested for suspended sediment concentration (SSC) using Method 2540 D of the American Public Health Association. Water depth at the site is generally less than $1 \mathrm{~m}$ for most of the year (except for flood conditions) and comparison between surface grab and depth integrated manual samples, which were also taken, showed little difference between the SSC values of each method at the sampling location, as sufficient mixing occurs in the river cross-section. Manual sampled data is available at the site since 2004. In-situ turbidity was continuously monitored using a Campbell Scientific OBS 3+ probe connected to a CR800 logger recording at 15 minute intervals. The turbidity meter was installed at the hydrometric site in February 2010 by Cork Institute of Technology and has been in operation since then. The data from the turbidity 
meter analysed and presented in this paper is for the one year period from February 2010 to February 2011.

An additional set of suspended sediment and bed load samples is currently being collected as part of a river monitoring programme supported by the OPW. This work involves gathering manual suspended sediment samples and bed sediment samples at the location of each of the five water level gauging stations on the river. This sampling and testing programme commenced in April 2012 and is on-going.

Manual grab samples were also tested for a range of species of phosphorous: total $\mathrm{P}$ (TP), soluble reactive $\mathrm{P}$ (SRP), total reactive $\mathrm{P}$ (TRP), total dissolved $\mathrm{P}$ (TDP) and particulate P (PP). TP and SRP were determined by PhosVer3 Acid Persulfate Digestion/Photometric Method 8190. The procedure is equivalent to USEPA Method 365.2. The PhosVer3 Ascorbic Acid Method 8048 was performed to determine concentrations of TRP and TDP. PP is the difference between TP and TDP. Standard water samples were included in the analysis of all chemical constituents as accuracy checks. This programme of testing of phosphorous species was also undertaken from February 2010 to February 2011.

\section{Results and discussion}

The recorded rainfall for the study period was $878 \mathrm{~mm}$ at the nearest rain gauge station at Cork Airport which is $72 \%$ of the annual mean of $1219 \mathrm{~mm}$. Average daily flow rate (Q), total daily rainfall and the turbidity based sediment signal over the period of analysis is presented in fig. 2 . Although the study period was a relatively dry period, analysis indicates that the actual rainfall discharge from the catchment during the study period was higher than the long term average rainfall
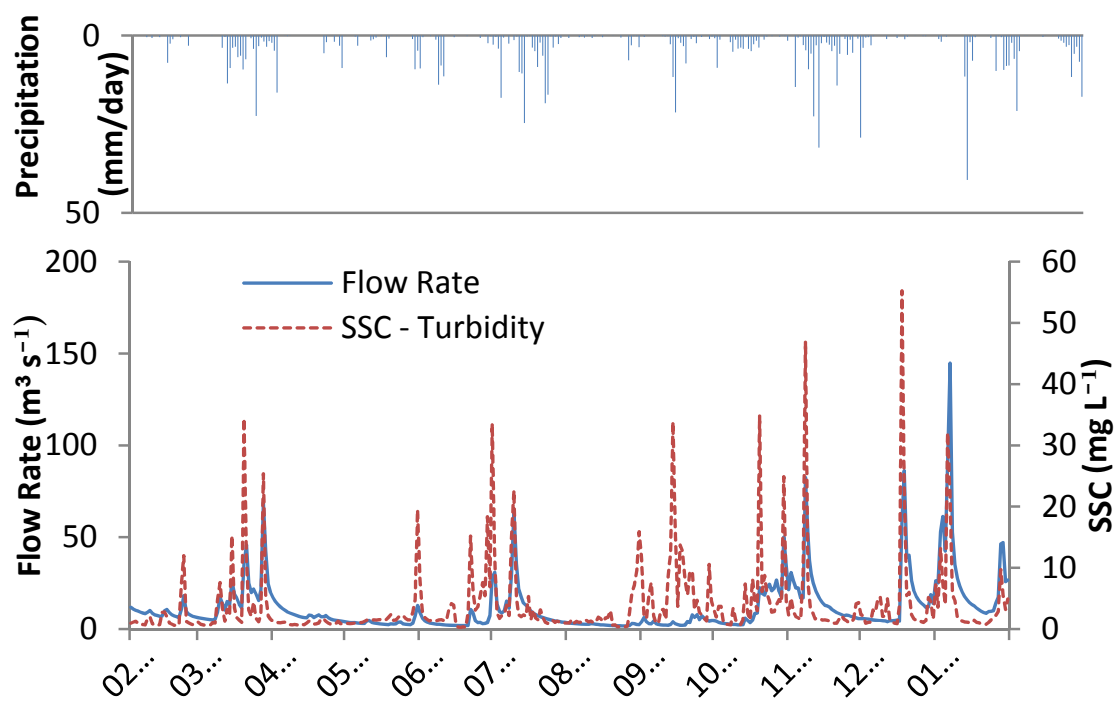

Figure 2: $\quad$ Precipitation, flow rate and SSC signal for the River Bandon. 
discharge implying increased overland runoff or base flow or both during the study period, relative to the long term average.

\subsection{Turbidity - suspended sediment concentration calibration}

A linear regression analysis was undertaken between suspended sediment concentration (based on manual samples) and results from the in-situ turbidity probe at Curranure. A good linear relationship between in-situ turbidity and SSC was found with an $r^{2}$ value of $0.871(n=72$ samples; $p<0.005)$. In-situ turbidity measurements at the Curranure gauging station were then converted to SSC using this linear relationship.

\subsection{Suspended sediment loads}

Suspended sediment loads can be estimated using the theoretical load equation where continuous data is available or using a rating curve approach where such continuous data is not available and only non-continuous data is available; this is generally representative of Irish river catchment conditions.

The theoretical load of suspended sediment (or any water quality parameter) transported over a given time interval is:

$$
\mathrm{L}_{\mathrm{s}}=\int_{\mathrm{t}_{1}}^{\mathrm{t}_{2}} \mathrm{Q}_{\mathrm{t}} \mathrm{SSC}_{\mathrm{t}} \mathrm{dt}
$$

where $L_{s}$ is the load over a time period $\left(t_{2}-t_{1}\right), Q_{t}$ is the flow rate at time $t$ and $S S C_{t}$ is the suspended sediment concentration at time $t$, and $d t$ is the time interval $\left(\mathrm{t}_{2}-\mathrm{t}_{1}\right)$. SSC is measured in $\mathrm{mg} \mathrm{L}^{-1}$ and $Q$ is measured in $\mathrm{m}^{3} \mathrm{~s}^{-1}$ yielding $L_{\mathrm{s}}$ in $g$ for the selected time period; this equation may also be presented in its discrete form.

The annual true load passing the Curranure gauging station was found to be 6012 tonnes equating to a suspended sediment yield value of $14.2 \mathrm{t} \mathrm{km}^{-2} \mathrm{a}^{-1}$. Fig. 3 presents monthly suspended sediment loads (dark profile) and average flow rates over the study period; the highest sediment loads occur during the winter months (67\% over the months of November, December and January) indicating the primary, though not exclusive, influence of flow on sediment load.

The rating curve approach was applied on the River Bandon [3] to generate SSC -Q relationships using the manually sampled data from 2004 to 2011. The linear regressive approach yields the following relationship between SSC and Q:

$$
\log \mathrm{SSC}=\log \alpha+\beta \log \mathrm{Q}
$$

where $\alpha$ and $\beta$ are the constants of the linear regression. When detransformed to normal space this gives a log-linear regression of the form [4]:

$$
\operatorname{SSC}=10^{\alpha} \mathrm{Q}^{\beta}
$$

Another common approach is the power regression fit given as:

$$
\mathrm{SSC}=\sigma Q^{\tau}
$$

where $\sigma$ and $\tau$ are the constants of the non-linear regression. 


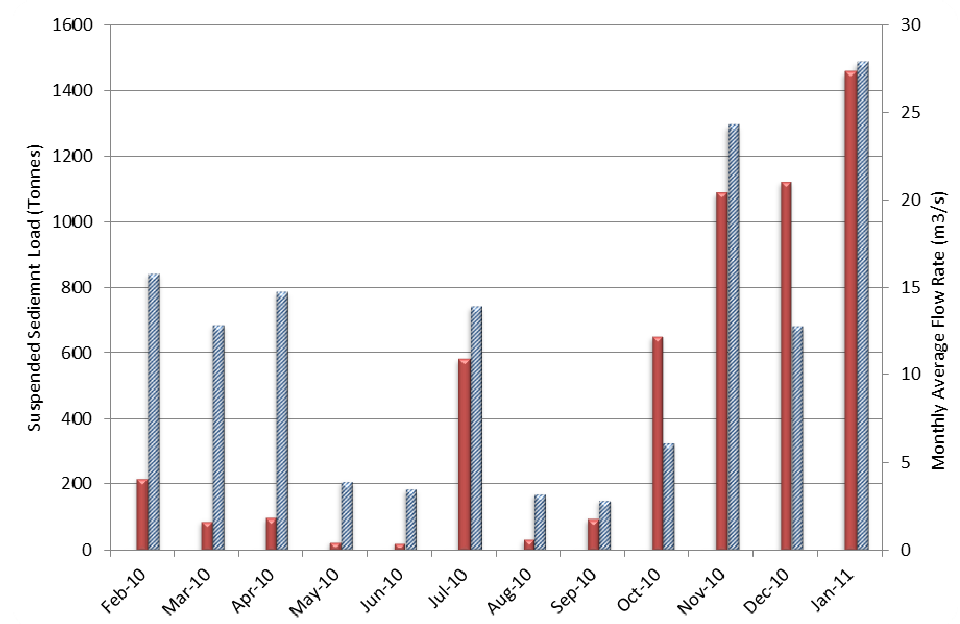

Figure 3: Monthly suspended sediment load and flow rate for the study period.

Both regression approaches were applied to generate SSC-Q relationships which were then used to estimate suspended sediment loads (which could then be compared to the true load). The data was also separated by stage (rising or falling limb), by season and analysed as daily flow data. The log-linear regression curve was found to be most accurate for load comparison, with the annual load estimates using this approach exhibiting an error range from $9 \%$ to $18 \%$ error with the errors being primarily negatively biased. A possible explanation for this underestimation is that whilst manual samples were taken on the River Bandon up to very high flows (the maximum sampled flow rate was $209 \mathrm{~m} 3 / \mathrm{sec}$ ) these did not correspond to very high SSC values (a maximum sample SSC of $117 \mathrm{mg} / \mathrm{l}$ compared to a maximum recorded SSC value of 979 $\mathrm{mg} / \mathrm{l}$ ) and thus the full disproportionate effect of these high SSC values on loading is not included. The use of the power regression curve, on the other hand, involved annual load estimation errors of up to $50 \%$. The use of stage or seasonal separation did not result in a significant improvement in the load estimates at either a monthly or annual scale. The $\alpha$ and $\beta$ constants for the full data set were 0.802 and 0.701 respectively, with a regression coefficient of 0.342 $(\mathrm{p}<0.005)$. These constants varied significantly for seasonal and stage separation analyses. It may be concluded from the analysis that the rating curve approach can provide good estimates of the annual load which has particular relevance and potential importance in a general Irish context where the current database of suspended sediment information is very limited.

\subsection{High flow storm based events}

Suspended sediment transport on the river is characterised by the disproportionate effect of high flow events. Analysis of high flow events over the 
study period identified one large storm in January, 2011 which for purposes of analysis is defined as having a return period of more than two years; this storm had a peak $\mathrm{Q}\left(\mathrm{Q}_{\text {peak }}\right)$ of $185 \mathrm{~m}^{3} / \mathrm{sec}$. This storm of 68 hour duration transported approximately 1015 tonnes, over $16 \%$ of the total annual load. Two separate medium sized storms (defined here for analysis purposes as having a return period between one and two years) in November and December 2010 transported loads of 624 tonnes $\left(Q_{\text {peak }}=101 \mathrm{~m}^{3} / \mathrm{sec}\right)$ and 991 tonnes $\left(Q_{\text {peak }}=105 \mathrm{~m}^{3} / \mathrm{sec}\right)$ for storm durations of 96 and 74 hours respectively; these two storms contributing a further $27 \%$ of the annual load. The SSC and flow rate signals for January, 2011 including the storm event are shown in Fig. 4. This shows that the peak in SSC generally occurs before $Q_{\text {peak }}$ for each event in January, which is typical for flood events on the River Bandon.

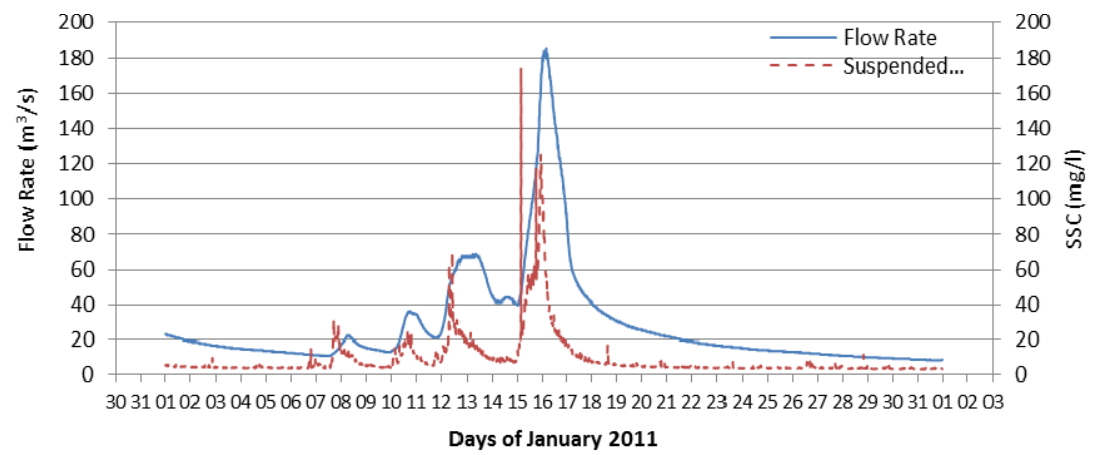

Figure 4: $\quad$ SSC and flow rate signal for January 2011.

\subsection{Hysteresis of the SSC-Q relationship}

Hysteresis is commonly observed in the relationship between SSC and flow rate when peak SSC occurs either before or after $\mathrm{Q}_{\text {peak }}$. Harrington and Harrington [5], for example, identified this phenomenon for the nearby small scale River Owenabue catchment. Different classes of SSC-Q relationships may be found including the three main relationships: straight or curved single lines, clockwise loops and anticlockwise loops. An analysis of high flow events over the study period showed the dominance of clockwise loops, seven out of nine events identified were clockwise loops, one anti-clockwise loop and one mixed loop was also identified. The most common explanation for clockwise loops is a combination of sediment exhaustion and close proximity of the sediment source to the monitoring station [6, 7]. Fig. 5 shows the hysteretic clockwise loop for the storm event presented above in January, 2011. It shows the higher SSC values on the rising limb of the hydrograph relative to the falling limb. This most common loop indicates the predominant likely supply limited sediment behaviour of the river. 


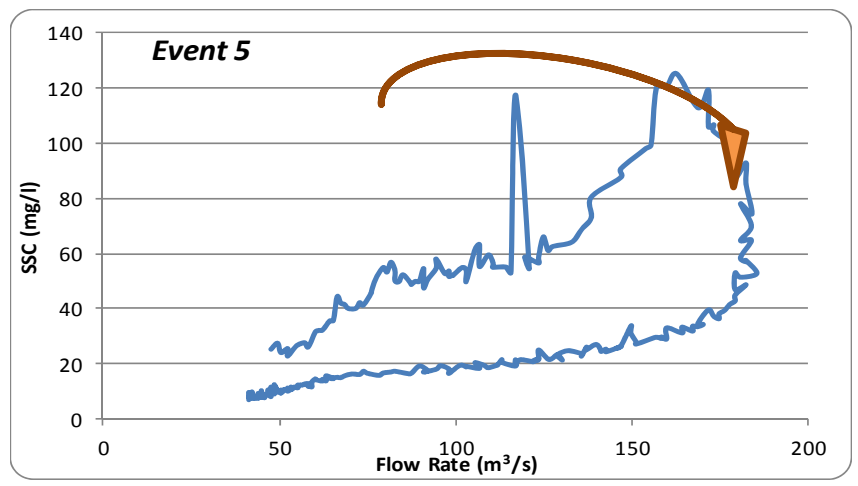

Figure 5: $\quad$ Clockwise Hysteretic Loop for January 2011 Storm.

\subsection{Phosphorous loading}

Linear regression analyses were undertaken to determine the relationships between flow rate, SSC and the individual $\mathrm{P}$ species. Table 1 presents a correlation matrix of the $\mathrm{r}^{2}$ values for each set of parameter relationships, fig. 6 presents greater detail. Flow rate (Q) and SSC were positively correlated with all $\mathrm{P}$ species and high correlations were achieved for SSC with some individual $\mathrm{P}$
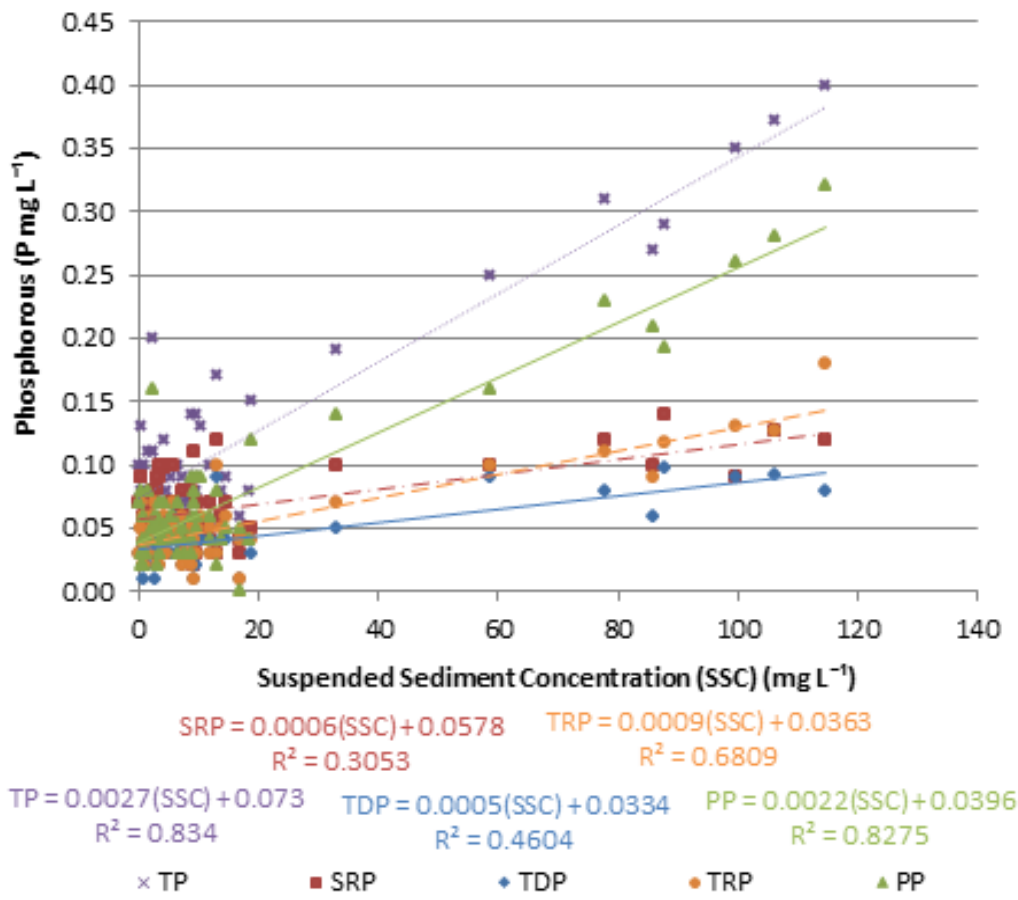

Figure 6: Relationship between P species and SSC. 
parameters; the highest $r^{2}$ value was found for the SSC-TP regression $\left(r^{2}=\right.$ 0.834), while the lowest $r^{2}$ value was for the SSC-SRP regression. These results may be anticipated given that TP is primarily particulate while SRP is not. Similar SSC-P relationships have also been found for other Irish studies [8, 9].

Table 1: Correlation matrix of $\mathrm{r}^{2}$ values from linear regression.

\begin{tabular}{|c|c|c|c|c|c|c|}
\hline & $\mathbf{Q}$ & SSC & TP & SRP & TRP & TDP \\
\hline SSC & 0.679 & & & & & \\
\hline TP & 0.520 & 0.834 & & & & \\
\hline SRP & 0.254 & 0.305 & 0.504 & & & \\
\hline TRP & 0.432 & 0.681 & 0.816 & 0.611 & & \\
\hline TDP & 0.369 & 0.460 & 0.639 & 0.608 & 0.764 & \\
\hline PP & 0.487 & 0.828 & 0.962 & 0.392 & 0.699 & 0.443 \\
\hline
\end{tabular}

The linear regression analysis allowed the 15 minute instantaneous $\mathrm{P}$ concentrations to be generated from the SSC record. P loads $\left(\mathrm{L}_{\mathrm{p}}\right)$ could then be calculated using the discrete load equation:

$$
\mathrm{L}_{\mathrm{p}}=\sum_{\mathrm{i}=1}^{\mathrm{n}} \mathrm{C}_{\mathrm{i}} \cdot \mathrm{Q}_{\mathrm{i}}
$$

The annual TP load was found to be 42.9 tonnes which equates to only $0.7 \%$ of the total suspended sediment flux. The PP load of 27.6 tonnes accounts for $64.3 \%$ of the TP load indicating that PP dominates the P transfer in the river. The TDP load is smallest with an annual load of 15.4 tonnes or $36 \%$ of the TP load. The SRP and TRP loads were found to be 24.7 and 19.0 tonnes/year respectively.

Monthly TP loads were found to be highest during the winter months of November, December and January which may be explained by the natural plant decay increasing $P$ levels in the winter months combined with the high flow rates which are also generally experienced in the winter months. However this pattern can be disrupted by the impact of storm events which generate higher levels of SSC and thus higher P levels. Such a storm event with increased P loading was experienced in July 2011 during the summer season.

\subsection{Bed sediments and bed load}

Bed load transport is a feature of sediment behaviour on some stretches of the river on high flow events. Median sediment sizes of the coarse sediments at the three gauging stations in the upper catchment range from approximately $5 \mathrm{~mm}$ to $20 \mathrm{~mm}$ size and it is clear from in-stream visual observation at these gauging stations that active bed load transport occurs on higher flows and that subsequent downstream sediment deposition also occurs. Bed rock is a prominent feature and influences the shallow channel profile. Bed load transport is also experienced on the river through the town of Bandon where some emergency dredging works have been completed in each of the past three years and where river improvement works are planned for Summer 2014 and 2015. 


\section{Conclusions}

This paper presents some sediment and nutrient behaviour aspects of the River Bandon, a medium sized river catchment in an Irish context. Suspended sediment transport dominates but bed load transport is also a feature on river stretches at higher flows.

Turbidity has been found to be a suitable surrogate for SSC allowing suspended sediment loadings to be analysed from the continuous turbidity data. Similarly SSC has been found to correlate well with Total and Particulate Phosphorous allowing, by extension, phosphorous loadings to be analysed using the continuous turbidity data.

The annual suspended sediment load for the study period was estimated at 6012 tonnes with a total annual phosphorous load of 42.9 tonnes; particulate phosphorous dominates the $\mathrm{P}$ transfer in the river.

The suspended sediment load is primarily controlled by river flow with supply limited transport a feature of the system. The P load is influenced by suspended sediment transport in conjunction with seasonal impacts. Infrequent high flow events contribute disproportionately to both suspended sediment and phosphorous transport.

\section{Acknowledgements}

The authors wish to acknowledge the research funding received from the Government of Ireland/Institutes of Technology Technological Sector Research Strand I Postgraduate R\&D Skills Programme and the Office of Public Works. The authors also wish to acknowledge the support received from the Environmental Protection Agency and the Office of Public Works for providing river flow rates and associated data and other information. The authors also wish to thank John Clancy, Kevin Motherway and James Hickey for their contribution to this work.

\section{References}

[1] Cork County Council, Water matters: Our plan! South Western River Basin Management Plan (2009-2015), 2010.

[2] RPS Consulting Engineers, Cork County Council, Bandon Flood Early Warning System, 2010.

[3] Harrington, S.T., Harrington, J.R, 'An assessment of the suspended sediment rating curve approach for load estimation on the Rivers Bandon \& Owenabue, Ireland', Geomorphology, 185, 27-38, 2013.

[4] Ferguson, R.I., 'Accuracy and precision of methods for estimating river loads’, Earth Surface Processes and Landforms 12, 95-104, 1987.

[5] Harrington, S.T., Harrington, J.R., 'The influence of storm based events on the suspended sediment flux in a small scale river catchment in Ireland', 6th International Conference on River Basin Management, May 2011, Riverside, California, USA, 2011. 
[6] Lenzi, M.A., Marchi, L., 'Suspended sediment load during floods in a small stream of the Dolomites (northeastern Italy)', Catena 39, 267-282, 2000.

[7] Rodríguez-Blanco, M.L., Taboada-Castro, M.M., Pallerio, L., TaboadaCastro, M.T., 'Temporal changes in suspended sediment transport in an Atlantic catchment, NW Spain', Geomorphology, Vol. 123, 181-188, 2010.

[8] Scanlon, T.M., Kiely, G. and Xie, Q. (2004). 'A nested catchment approach for defining the hydrological controls on non-point phosphorus transport', Journal of Hydrology, 291, 218-231, 2004.

[9] Jordan, P., Menary, W., Daly, K., Kiely, G., Morgan, G., Byrne, P., and Moles, R., Patterns and processes of phosphorus transfer from Irish grassland soils to rivers - integration of laboratory and catchment studies. Journal of Hydrology, 304, 20-34, 2005. 